\title{
Agent-Based Modeling of the Adoption of High-efficiency Lighting in the Residential Sector
}

Jinjian Cao School of Industrial Engineering, Purdue University, ca0164@purdue.edu Chul Hun Choi School of Industrial Engineering, Purdue University, choi270@purdue.edu Fu Zhao School of Mechanical Engineering/Division of Environmental and Ecological Engineering, Purdue University, fzhao@puedue.edu (Corresponding author)

\begin{abstract}
.
Due to the wide use of incandescent lighting, residential sector has much lower energy efficiency comparing to commercial sector. However, adoption of compact fluorescent (CFL) and light-emitting diode (LED) technology in residential sector has been slow because of several obstacles such as high price tag, poor public information, and additional cost to achieve favorable lighting features. A deep understanding on consumer's behavior is needed to support policy development in order to speed up the penetration of CFL and LED in the residential sector. Agent-based modeling (ABM) has been used to capture the dynamics of complex sociotechnical systems, and represent a suitable tool. Previous work on ABM of consumer adoption of CFL and LED rely heavily on multi-criteria decision making of the agents. Since light bulbs are not a significant purchase for most households, it is highly possible that customers will not go through complex decision making mechanics. This research establishes an ABM of residential lighting purchase and usage within a hypothetical community and tries to illustrate possible adoption paths under different scenarios. Agents are divided into three groups with different simple decision heuristics when making purchase. Energy consumption and greenhouse gas (GHG) emission from each scenario are calculated and compared. Results of the simulation show that incandescent lamps will eventually fade out of the market even with no policy implemented. After 25 years, annual energy consumption can be reduced by roughly $30 \%$ compared to Year 2010. Under best case where incandescent bulbs are banned, the energy consumption reduction can be up to $70 \%$. Among scenarios, incandescent ban and energy saving campaign yield best energy consumption and GHG emission reduction results. LED technology advancement can improve market penetration of LED lighting but has little effect on incandescent fade out. It is also shown that lighting technology retrofitting can achieve higher reduction on electricity consumption and GHG emission than electricity grid improvement.
\end{abstract}

Keywords: $\quad$ agent based modeling; high efficiency lighting; simple decision heuristics 


\section{Introduction.}

Residential and commercial lighting is an important contributor to total electricity consumption in U.S. According to U.S. Energy Information Administration [1], in 2014 about 412 billion kWh of electricity was consumed by residential and commercial sector in U.S., which is roughly $11 \%$ of total U.S. electricity consumption. Between them, residential lighting consumed 150 billion $\mathrm{kWh}$, which is about half the amount of commercial sector consumption. However, a report published by U.S. Department of Energy characterizing the lighting market of 2010 pointed out that residential sector had similar lamp density and average lamp wattage comparing to commercial sector, whereas only $1 / 6$ of average operating hours [2]. The main reason for the low energy efficiency in residential sector is the wide usage of incandescent lighting, including traditional incandescent lamps and halogen lamps.

Due to their low efficiency, incandescent lamps consume more electricity and generate more greenhouse gas (GHG) emission to deliver the same luminance comparing to other lighting technologies. Two types of lighting, compact fluorescent lamp (CFL) and light-emitting diode (LED) lamp are considered as "greener" alternatives to incandescent lighting due to their high energy efficiency. An estimates suggests that if incandescent lamps are banned globally by year

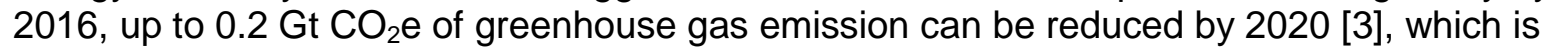
equivalent to the total carbon footprint of 10,000 cars with each one driving $100,000 \mathrm{~km}$. To offer a comprehensive understanding on the environmental performance of the lighting technologies, several life-cycle assessments that compare incandescent lamp with CFL and LED to evaluate retrofitting benefits had been carried out recently [4] - [7]. U.S. Department of energy conducted a detailed LCA study [4], including a summary to previous studies and a new LCA result to compare incandescent, CFL and LED lighting. Shahzada et al. [5] estimated that to produce 20 million lumen-hours of light, CFL lighting will have $50 \%$ reduction on Sustainable Process Index (SPI) footprint and carbon footprint comparing to incandescent lighting, whereas LED lighting will have $75 \%$ reduction on these two impact categories. In another study, Bergesen et al. [6] suggests that CFL lighting will have 60\% reduction in 13 of $14 \mathrm{impact}$ categories considered including GHG emission comparing to incandescent lighting, while LED lighting will have $80 \%$ reduction. Franz et al. [7] compared environmental impact of incandescent lighting with several different assumptions of LED lighting and the worst case results in roughly $70 \%$ reduction of GHG emission. Despite these environmental advantages, the adoption of CFL and LED in residential section is much slower than commercial sector. A market report from National Electrical Manufacturers Association shows that during the first quarter of 2015, incandescent lighting, including halogen lamps, still accounts for $53.7 \%$ of the total consumer lamps market, whereas CFL lighting claims $40 \%$ of the market share and LED lighting has only $6.3 \%$ [8]. For commercial buildings, CFL lighting already owned over $90 \%$ of market share.

This situation did not remain unnoticed. According to NEEA, over half of stores in northwest region of U.S. had promotional material on lighting replacements since 2013, and various promotions including advertisement flyers, brochures, demonstrations, and websites were conducted [9]. Efforts have been made to develop residential sector energy consumption model to provide insights on the problem. Richardson, I. et al. [10] presented a time-series based bottom-up model to estimate residential lighting energy demand. In their research, an active time series of occupancy was used to calculate the number and time of lighting equipment utilized, with consideration of outdoor irradiance level. The result was compared to historical data and proved to be with high accuracy. Johnson, B. J. et al. [11] used a Markov chain based approach to model residential energy consumption. The research established a statistical model to represent the activities of different types of occupants during a day and estimated energy 
consumption accordingly. Meanwhile, predictions of future residential market penetration and energy consumption level are made by several reports and researches. NEEA report [9] presented a residential lighting market share penetration based on expert opinion, predicting that CFL and LED lighting in total will have $49 \%$ of market share in year 2016 , and $69 \%$ of market share in year 2018. DOE report [12] presented a top-down model to predict market penetration and energy consumption. In the model, consumers are cost conscious and the market penetration is calculated by logit regression models based on historical and predicted costs with consideration of technology diffusion curve. The result showed that energy consumption can be reduced by $37 \%$ at year 2020 and $67 \%$ at year 2030 . However, it should be noted that consumers may consider factors other than cost when making decisions. To address the issue, two groups of researchers tried to characterize future residential lighting market with corresponding energy and environmental consequences with agent-based modeling (ABM) approach with consideration of different decision making criteria [13] - [14]. Residential lighting market consists of multiple parallel households exposed to market information and regulations, which are likely to have different criteria to make decision and change their decisions over time. Therefore, a self-evolving and bottom-up model is desired if one wants to study the long term evolution of the market. ABM adopts a bottom-up computational approach with "agents" imitating actors in real world events. Agents make interactions with each other and the "environment", which is the representation of corresponding conditions, restrictions, and situations in the real world [15]. These features make ABM a suitable tool to simulate residential lighting market for its bottom-up nature and the ability to evolve through agent-to-agent and agent-to-environment interactions.

Among the two ABM studies on residential lighting, Chappin et al. [13] established a networkbased agent based model to illustrate energy consumption and GHG emission reduction of residential lighting. In their model, agents made decisions by multi-criteria decision making process with different weights distribution. Agents will also adjust their weight by recent experience and social network information exchange. Detailed lighting products differences were considered with difference in technology, light color, slot type, etc. Several scenarios were explored to show the effect of possible policies. Their result indicated that incandescent lamps will still be the dominant technology after 40 years without policy support, and incandescent ban will be the most effective policy to reduce energy consumption and GSG emission. Hicks et al. [14] present a grid-based agent based model to illustrate possible rebound effects due to energy saving from adopting new technologies. In their model, agents first made random decisions based on a utility function coming from multi-criteria decision results. A survey was carried out to support the multi-criteria decision weighting data. Agents exchanged their opinion with their grid neighbors. Different rates of rebound effect and two possible scenarios were considered. Their result indicated that households will swiftly switch to new technologies, but with high rates of rebound effect, energy consumption may not be reduced.

It should be noted that both of the ABM studies on residential lighting (i.e., Chappin, E. J., et al. 2013; Hicks, A. L., et al. 2015) rely heavily on multi-criteria decision making from the agents. Early in 1979, Olshavsky et al. pointed out that such decision making process may not be realistic when facing a purchase that is not important [16]. Later, Hoyer made an experiment to show that most customers make very quick in-store choices by simple heuristics on a single criterion when purchasing common product like detergents [17]. Since lighting bulbs are not a significant purchase for most households, it is highly possible that customers will not go through complex decision making mechanics. Meanwhile, Chappin et al. did not consider use phase cost as a decision-making criterion. However, CFL and LED equipment is actually cheaper considering use phase cost and most CFL and LED lighting products will state this on their package. Also, since the research is conducted in Netherland, several parameters including 
number of lamps per household, average hours per lamp were different from U.S. situation. In model created by Hicks et al., although the agents make stochastic decisions, their utility function are pre-determined and cannot illustrate possible opinion changes of the public. To address these issues, this research aims to establish an ABM of residential lighting purchase and usage within a community and try to illustrate possible adoption paths under different scenarios. Agents, divided into groups, are applied with simple decision heuristics. The model provides market penetration and total energy consumption estimation of three types of lighting bulbs used in residential sector (i.e., incandescent lamp, CFL, and LED) over time.

\section{Investigative Method.}

This research models residential lighting purchase choice within a hypothetical urban residential community with 500 households using network based ABM approach. To calculate electricity consumption and lifespan of lighting equipment while keeping reasonable simulation speed, the time step of the model is one day. The simulation starts at year 2010 and ends after 25 years (Year 2035, 9125 days), which allows model validation using historical data while capture the market penetration process of CFL and LED. The model is implemented under Repast Simphony 2.3.1 [18]

Each household is considered as an agent within a Watts Beta Small World network, which imitates social influence network [19]. Following the average data from USDOE [20], each agent will have a random number of lighting positions following a triangular distribution between 5 and 120 with mean 65, each in need of one light bulb. Also, for each specific lighting position, use time per day is assigned with a triangular distribution random number between 0 and 6 hours with a mean of 2 hours. The range of lighting positions follows the data from USDOE [20], and the range of use time per day is assumed to be the maximum range possible of triangular distribution.

To simplify the model, type of lighting is limited to traditional incandescent lamp, spiral CFL lamp, and LED lamp, with the assumption that these lamps are fully substitutable by each other when used for lighting. Each lighting bulb is treated as $60 \mathrm{~W}$ equivalent and with average shelf price. The life span of each bulb is a random number following an exponential distribution with average corresponding to lighting type (1000 hours for incandescent, 10000 hours for CFL, and 25000 hours for LED). Further differences between lighting bulbs are excluded, such as colors, brands, and other features. Energy consumption during manufacture phase for the bulbs [4] is also included in the model to show the difference between total energy consumption and use phase energy consumption. Since the price and efficiency of incandescent and CFL bulbs are relevantly stable comparing to LED since 2010 (60W and $\$ 1.39$ for traditional incandescent, 14W and $\$ 3.70$ for CFL), these parameters are considered as constant for simplification [1], [9]. For LED equipment, USEIA report pointed out that both bulb cost and efficiency changed linearly (decreasing and increasing, respectively) during 2010-2014 [1]. At the beginning of the simulation (year 2010), LED bulbs cost $\$ 68.00$ with a rating of 16W [4]. At year 5 (year 2014), LED bulbs cost $\$ 11.14$ with a rating of $10 \mathrm{~W}$ [9]. Both of these parameters are assumed to change linearly at an annual basis ( $\$ 11.374$ and $-1.2 \mathrm{~W}$, respectively) between 2010 and 2015 . Price drop and energy efficiency increase of LED bulbs due to technology advancement after 2015 will be discussed in scenario analysis. Besides, average U.S. residential electricity price at year 2010 ( $\$ 0.115$ per $\mathrm{kWh}$ ) and a linear increment from historical data ( $\$ 0.002$ per $\mathrm{kWh})$ is applied over simulation period [21]. To calculate energy consumption other than use phase, U.S. DOE life cycle assessment data $(0.53 \mathrm{kWh}$ per incandescent bulb, $15.75 \mathrm{kWh}$ per CFL bulb, 95.27 kWh per LED bulb) are used [4]. 
In order to address carbon footprint reduction from residential high-efficiency lighting adoption, use phase greenhouse gas (GHG) emission and total greenhouse gas emission including manufacturing, transport and disposal phase are calculated in a bottom-up manner. All use phase $\mathrm{GHG}$ emission ( $0.518 \mathrm{~kg}$ carbon dioxide equivalent $\left(\mathrm{kgCO}_{2} \mathrm{e}\right)$ per $\mathrm{kWh}$ ) from electricity consumption is treated as U.S. average electricity grid emission and calculated from U.S. Environmental Protection Agency (EPA) electricity grid emission data [22] and all other GHG emission (0.968 $\mathrm{kgCO}_{2} \mathrm{e}$ per incandescent bulb, $9.167 \mathrm{kgCO}_{2} \mathrm{e}$ per CFL bulb and 16.269 $\mathrm{kgCO}_{2} \mathrm{e}$ per LED bulb) is calculated from U.S. DOE life cycle assessment data [4]. All GHG emission is assessed using 100-year GWP.

Whenever a bulb burned out, the agent will replace it with a new bulb at the beginning of the following day (since time step is one day). When facing the option to choose a bulb, either at the beginning of the simulation or when a bulb burns out, agents are divided into three groups: cost heuristic $(\mathrm{CH})$, self attitude heuristic $(\mathrm{SAH})$ and network attitude heuristic $(\mathrm{NAH})$. The actions an agent takes during each time step is summarized in Figure 1.

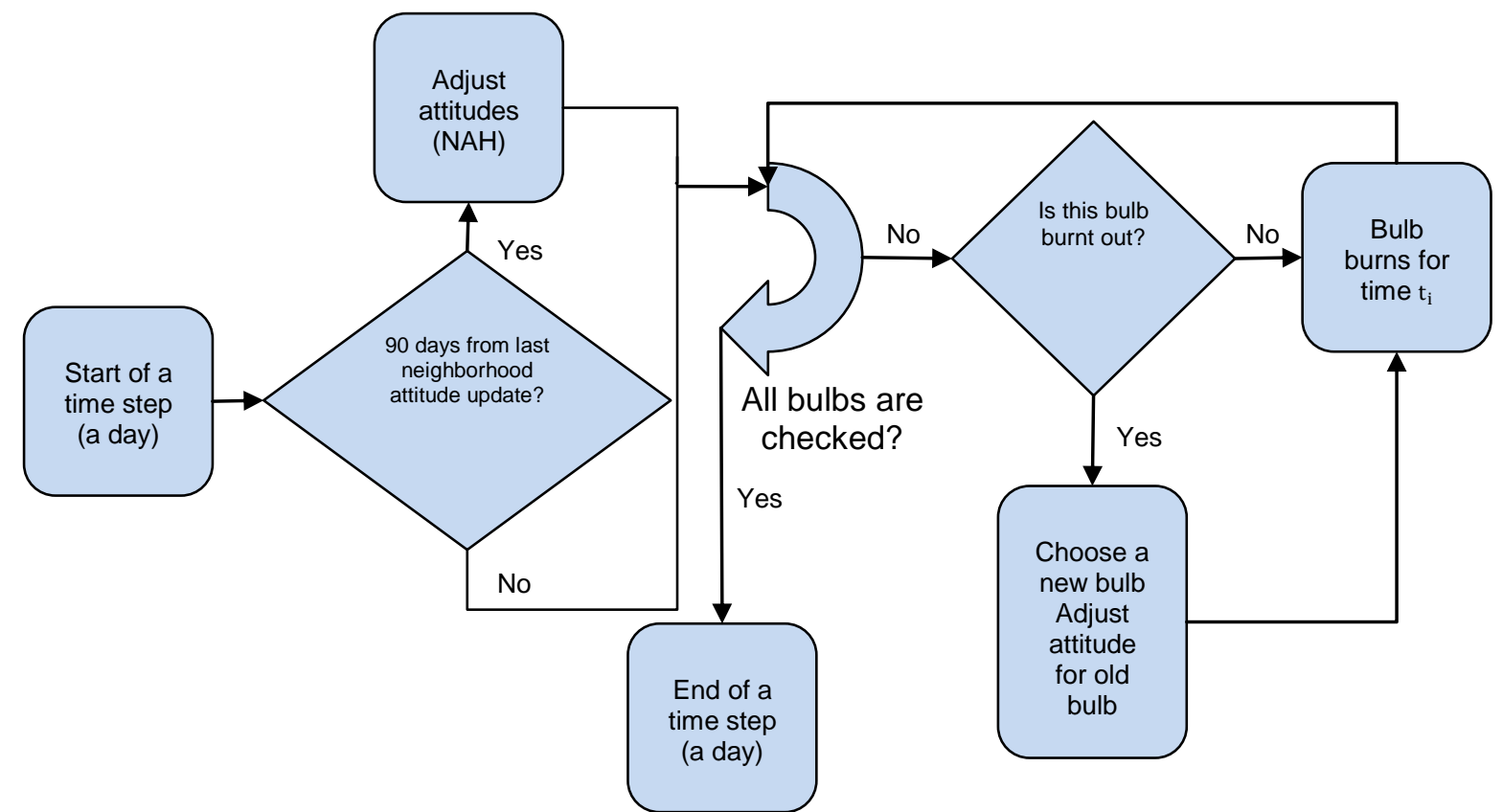

Figure 1: Agent Flow Chart. Actions an agent will take during a time step.

$\mathrm{CH}$ agents calculate the costs for each lighting position with different bulbs considering only a limited period of time from now. A predetermined random number $\mathrm{y}_{\mathrm{c}}$ following a triangle distribution between 0 and 20 with mean 10 represents the time period to calculate the costs. Taking current electricity price $p_{e}$, current bulb price $p_{j}(j=1$ for incandicent, $j=2$ for CFL, and $j=3$ for LED), current bulb efficiency $e_{j}$, average bulb life span $l_{j}$, and usage per day for position $i t_{i}$, the calculated cost for lighting position i with bulb type $j$ is:

$$
c_{i j}=p_{j} \times\left[y_{c} \times 365 \times t_{i} \div l_{j}\right]+p_{e} \times y_{c} \times 365 \times t_{i}
$$

To choose a new bulb, a $\mathrm{CH}$ agent compares calculated cost of three different lighting types for the lighting position and chooses the cheapest one. For a small purchase like this, households are unlikely to carry out a more complicated calculation involving the time value of money. Thus, discount rate and other possible cost adjustments are not included. 
$\mathrm{SAH}$ and NAH agents choose new bulb based on their attitude towards three different lighting types, representing their overall feelings (satisfaction, familiarity, etc.) towards them. SAH agents determine their attitudes solely based on their own experience, while NAH agents are also influenced by their neighbors. At the beginning of the simulation, each agent (including $\mathrm{CH}$ agents) is assumed to have an attitude level of 10 to incandescent bulbs, 1 to CFL bulbs and 0 to LED bulbs, reflecting the fact that at year 2010, incandescent bulbs were most well-known and LED bulbs were still unknown to most households. Every time an agent has a burnt-out bulb, the agent will adjust its attitude of that lighting type. It should be noted that $\mathrm{CH}$ agents will also adjust their attitudes in order to provide information for NAH agents. NEEA report includes a survey regarding satisfactory of CFL and LED customers [9]. Based on this, each time an agent adjusts their attitude towards CFL or LED bulbs and the adjustment value is randomly determined with probability shown in Table 1. For incandescent bulbs, the adjustment value is assumed to always be 2 , as incandescent bulbs have more pleasant features available like various size and shape selection, excellent color rendition, and instant turn-on time. Also, this adjustment is divided by the number of same-type bulbs currently used by the agent. This is to reflect the fact that the more bulbs an agent owns, the more unlikely the agent's opinion will be built on a single bulb. When adjusting attitudes, if an agent with attitude 0 towards LED lighting finds a neighbor using LED bulbs, the agent will change its attitude to 1 , representing that the agent receives information about LED from the neighbor. For NAH agents, an additional adjustment happens every 90 days. For each lighting type, an NAH agent adds attitudes from all neighbors together and find out the type with highest total neighbor attitude. The agent then adds 1 rank to its attitude towards that type.

Table 1: Probability Table of Attitude Adjustments

\begin{tabular}{|l|l|l|l|}
\hline Adjustment Value & Incandescent & CFL & LED \\
\hline+2 (Very satisfying) & $100 \%$ & $40 \%$ & $63 \%$ \\
\hline+1 (Satisfying) & $0 \%$ & $34 \%$ & $25 \%$ \\
\hline 0 (Somewhat satisfying) & $0 \%$ & $16 \%$ & $10 \%$ \\
\hline-1 (Unsatisfying) & $0 \%$ & $10 \%$ & $2 \%$ \\
\hline
\end{tabular}

To choose a new bulb, both SAH and NAH agents make stochastic decisions. Suppose a SAH or NAH agent has an attitude of $\mathrm{a}_{1}, \mathrm{a}_{2}$, and $\mathrm{a}_{3}$ towards incandescent, CFL, and LED bulbs respectively, the probability for the agent to choose type i as the new bulb is:

$$
\mathrm{p}_{\mathrm{i}}=\mathrm{a}_{\mathrm{i}} /\left(\mathrm{a}_{1}+\mathrm{a}_{2}+\mathrm{a}_{3}\right)
$$

Since this model is stochastic, multiple runs are required to reduce the effect of randomness. To do so, 10 runs are made first to construct a 95\% confidence interval and additional runs will be made if relative error of the interval is greater than 0.05 . The details of simulation technique can be found in [23].

By default, each agent will be assigned to a heuristic group with equal probability, resulting roughly equal population for the three heuristic groups. This in conjunction with all parameters mentioned above forms the base case of the model. In order to illustrate more possibilities of future and explore the effect of several possible policies, 5 scenarios are explored as below:

1. Cost-conscious community: In this scenario, we start with $60 \% \mathrm{CH}$ agents and $20 \%$ for both $\mathrm{SAH}$ and NAH agents. This is to show how the model will perform when a different population base is provided. 
2. Incandescent lamp ban: Starting from the 10th year (year 2020, 3650 days), no new incandescent bulbs can be bought. However, incandescent bulbs already installed can still be used until they burn out.

3. LED technology advancement: According to DOE projection, LED lighting efficiency will increase to 200 lumens per watt (4W LED as 60W incandescent equivalent) and price will fall to $\$ 3.34$ at year 2030. In addition to existing adjustment to LED price and efficiency, starting from year 5, LED lighting efficiency and price will adjust on an annual basis (at the rate of $-\$ 0.52$ per year for price, and $-0.4 \mathrm{~W}$ per year for wattage) until year 20 [1]. Also, a more conservative scenario where LED only advances at half speed $(-\$ 0.26$ and $-0.2 \mathrm{~W}$ per year until year 20$)$ is explored to show the impact of slow technology advancement.

4. Energy-saving campaign: In this scenario, all agents are influenced by a campaign to improve their attitude towards CFL and LED bulbs. The campaign will increase their attitudes towards CFL and LED by 1 every year starting in year 5 . A more effective scenario is also explored where agents' attitudes increase by 1 every 90 days.

5. Energy efficient incandescent: According to The Energy Independence and Security Act (EISA), 60W equivalent incandescent lamps should improve their efficiency to $43 \mathrm{~W}$ by the start of 2014. In response to this act, incandescent bulb rate in this scenario will be reduced to $43 \mathrm{~W}$ at year 5 .

6. Cleaner electricity grid: To compare the GHG emission reduction effects of residential lighting retrofitting and electricity grid retrofitting, this scenario uses projected GHG emission data from electricity sector and compares GHG emission with base case. The projected GHG emission per kWhr in 2035 of electricity grid is $88 \%$ of 2012 data [24].

7. Mercury issues with CFL lighting: It is highly possible that mercury content of CFL lighting will become a public concern. In this scenario, a \$3 CFL mercury tax will be in effect and attitude towards CFL will decrease by 1 at year 5 .

8. Rebound effect: As Hicks, A. L., et al pointed out, households may tend to extend their lighting hours or increase number of lighting after they switch into a more efficient option. In this scenario, after an agent switch to a more cost-efficient option for a lighting position, they will extend lighting hours of that position by $10 \%$. Also, they have a $10 \%$ probability to have a new lighting position.

\section{Model Verification and Validation.}

Several verification and validation techniques proposed for $\mathrm{ABM}$ are employed here to verify the model [25]. First, tracing technique is applied by observing the behavior of one single agent throughout a test run. This ensures that the model runs as designed. For each heuristic group, an agent is followed and no abnormal behavior is found. Secondly, 10 test runs are made with arbitrary random seed. The results are used for two purposes. An internal validity is made by observing the data range. The result is shown in Table 2. Besides, historical data, including EIA estimation and DOE estimation are applied to compare with test run results [1] [20]. The results, including critical parameters applied, are shown in Table 3.

From the internal validity test, it is apparent to see that the model itself is consistent. For the 10 test runs on the base case, no extreme results are observed and standard deviation of the 
output is smaller than $5 \%$ of mean value. When compare with historical data, base case results give an average lamp power close to DOE and EIA data at the beginning of the simulation. From data provided by EIA, it is also possible to estimate annual average energy consumption per household for year 2014. The result is presented as average lamp wattage. The model gives slightly lower energy consumption at the beginning but slower energy consumption reduction than EIA data. Still, the average wattage power is close to the historical data.

Table 2: Internal Validity Test

\begin{tabular}{|c|c|c|}
\hline \multicolumn{2}{|c|}{ Test data } & Base case \\
\hline \multirow{4}{*}{2010 Use Phase Energy Consumption (kWh) } & Min & 959331 \\
\cline { 2 - 3 } & Max & 1034983 \\
\cline { 2 - 3 } & Average & 997785 \\
\cline { 2 - 3 } 2014 Use Phase Energy Consumption \\
$(\mathrm{kWh})$ & stdev & 28518.51 \\
\cline { 2 - 3 } & Min & 852776 \\
\cline { 2 - 3 } & Max & 923704 \\
\cline { 2 - 3 } & Average & 888965 \\
\cline { 2 - 3 } 2034 Use Phase Energy Consumption \\
(kWh) & stdev & 25771.21 \\
\hline \multirow{4}{*}{$\begin{array}{c}\text { (kWh } \\
\end{array}$} & Min & 683557 \\
\cline { 2 - 3 } & Max & 753723 \\
\cline { 2 - 3 } & Average & 718692 \\
\cline { 2 - 3 } & stdev & 21213.67 \\
\hline
\end{tabular}

Table 3: Comparison with Historical Data

\begin{tabular}{|c|c|c|c|c|c|}
\hline Result & $\begin{array}{c}\text { Average } \\
\text { Number } \\
\text { of Lamps }\end{array}$ & $\begin{array}{c}\text { Average } \\
\text { Hour of } \\
\text { Use Per } \\
\text { Day (h) }\end{array}$ & $\begin{array}{c}\text { Average } \\
\text { Energy } \\
\text { Consumption } \\
\text { Per Day Per } \\
\text { Household } \\
2010(\mathrm{Wh})\end{array}$ & $\begin{array}{c}\text { Average } \\
\text { Lamp } \\
\text { Power } \\
2010(\mathrm{~W})\end{array}$ & $\begin{array}{c}\text { Average } \\
\text { Lamp } \\
\text { Power } \\
2014(\mathrm{~W})\end{array}$ \\
\hline Base case & 65 & 2 & 5467 & 42.1 & 37.2 \\
\hline DOE data & 67 & 1.6 & 4679 & 47.7 & $\mathrm{~N} / \mathrm{A}$ \\
\hline EIA data & 51 & 1.8 & 4223 & 46 & 39 \\
\hline
\end{tabular}

Finally, to address parameter variability, sensitivity analysis is conducted. To begin with, a selection of parameters coming from assumption and rough estimation are chosen, as shown in Figure 2. Each parameter will be modified by $\pm 10 \%$. To compare the sensitivity of parameters on the same basis, one run of each possible parameter setting with the same random seed is conducted and sensitivity of parameter is measured by changes on use phase annual energy consumption in year 2034 (final output). The result of sensitivity analysis shows that the model is reasonably robust. Most sensitive parameters are wattage of incandescent lamps, average hour of use per lamp, and average number of lamps per household. 


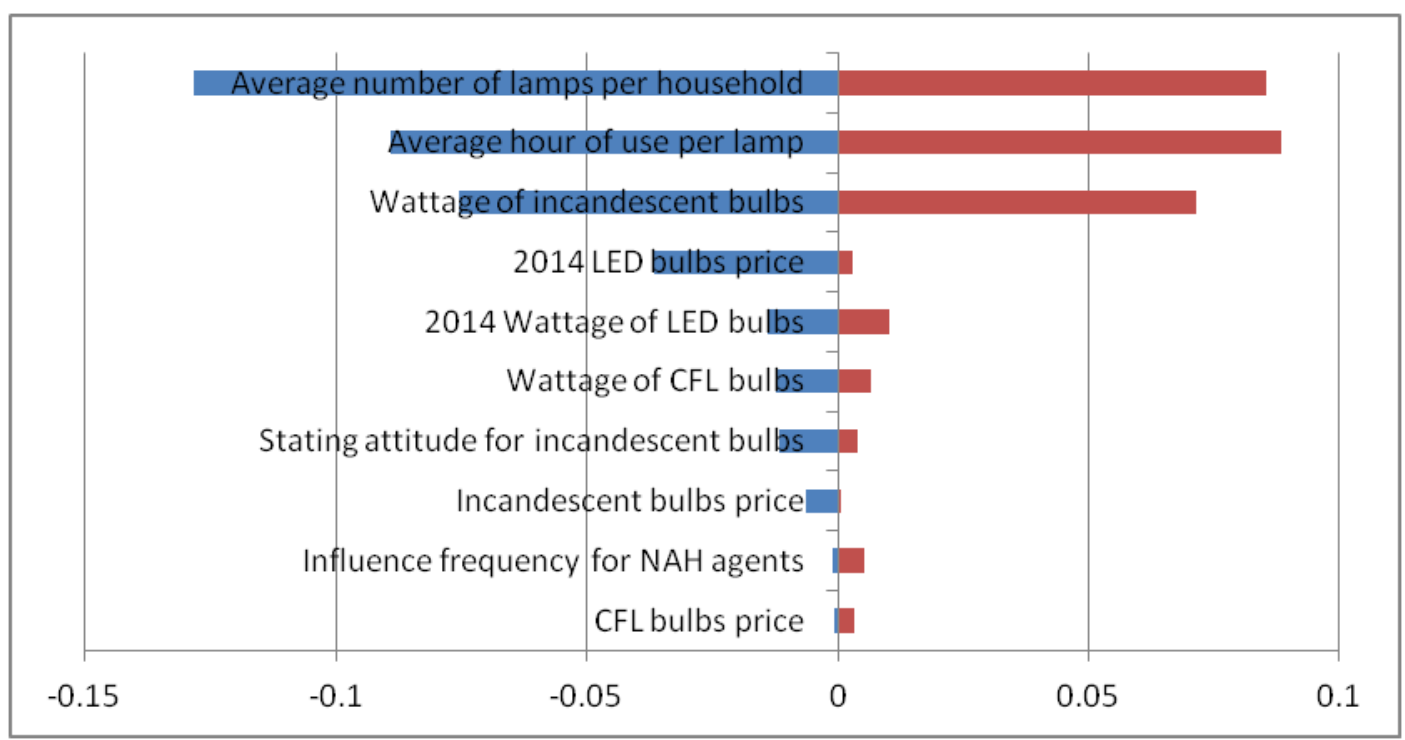

Figure 2: Tornado Graph

\section{Results and Discussion.}

Figure 3 to Figure 11 shows energy consumption, GHG emission, and shares of bulbs by technology of base case and each scenario. Since random effect in this model is relatively small, calculation result shows that relative error of confidence interval is smaller than 0.05 . Therefore, no additional runs are made. Also, the confidence interval is very tight (with half width less than $5 \%$ of the value). Therefore, to better illustrate the result, only mean value is plotted in the graph.
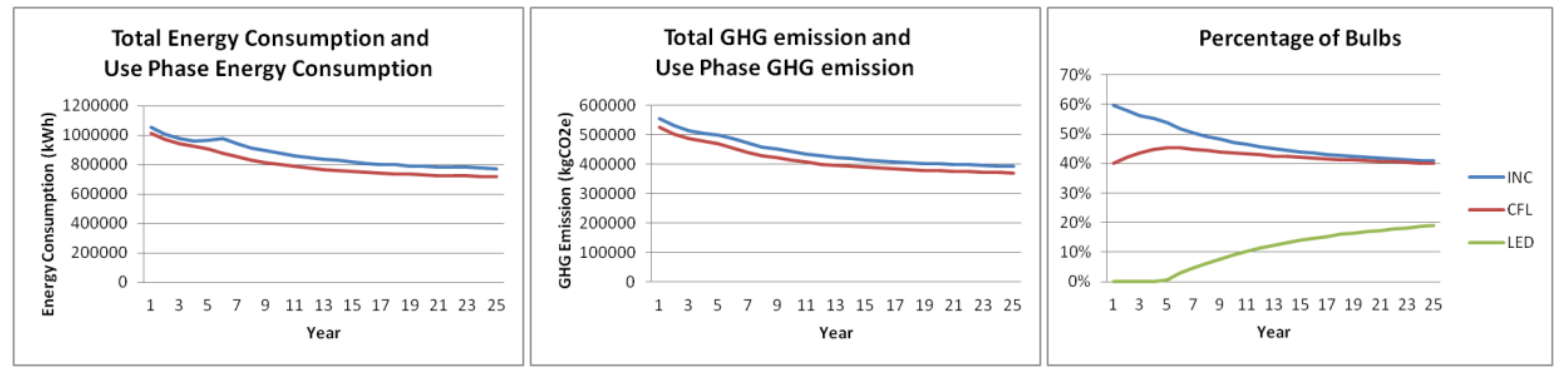

Figure 3: Base case results

For the base case, annual total energy consumption is reduced by $27 \%$ and annual use phase energy consumption is reduced by $30 \%$ at the end of simulation. Meanwhile, annual total GHG emission is reduced by $30 \%$. Incandescent bulbs are reduced to $70 \%$ of starting number, whereas the number of CFL bulbs remains roughly the same level for the whole simulation period. LED bulbs grow rapidly, holding $20 \%$ of market share at the end of simulation. The result shows that households are slowly adapting to high-efficiency lighting. However, without any interference, incandescent will remain the major technology at year 2035. Also, for total energy consumption, a spike can be observed around year 6 . This is due to much higher manufacturing energy consumption from CFL and LED lighting. When incandescent lighting is replaced by CFL and LED lighting intensively at year 6 , manufacturing energy consumption that year will increase greatly, which result in higher total energy consumption that year. 

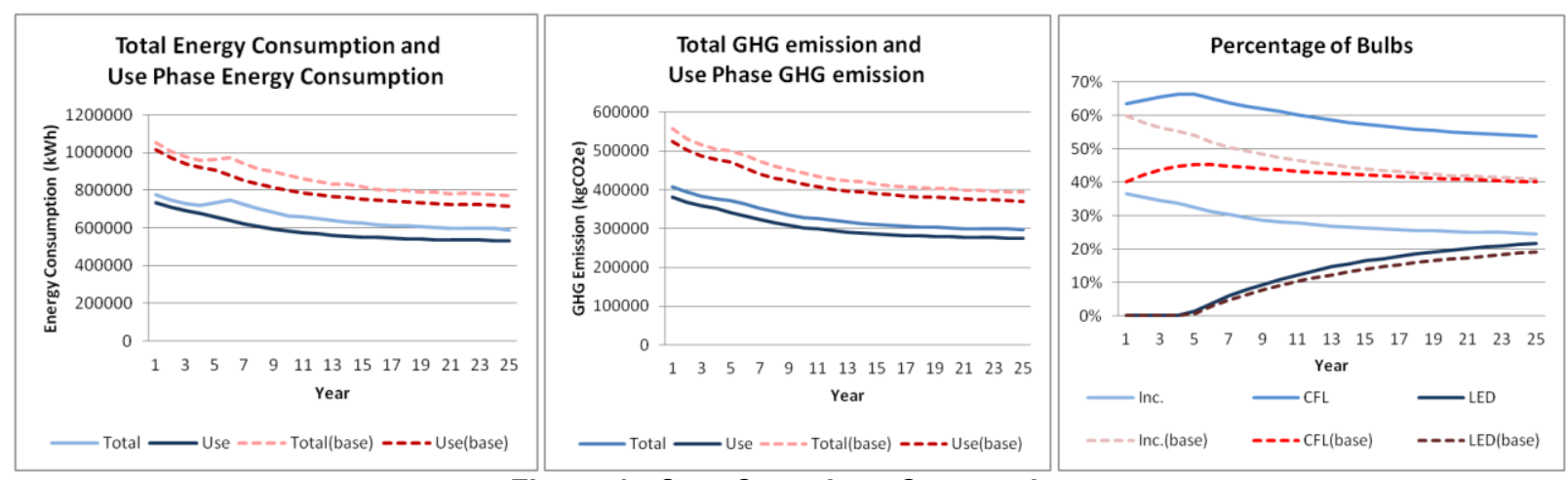

Figure 4: Cost Conscious Community

When the community has higher portion of cost heuristic households, CFL lighting becomes the leading technology at the beginning of simulation, as it is the most cost-effective under most situation. As a result, the starting energy consumption and GHG emission are roughly $72 \%$ of the base case. The trend of energy consumption and GHG emission reduction is similar to the base case. At year 2035, total energy consumption is reduced by $24 \%$ and total GHG emission is reduced by $28 \%$. Reduction rate is slightly smaller than the base case due to the fact that fewer inefficient lighting bulbs are installed at the beginning of simulation. It is apparent to draw the conclusion that cost-efficient households tend to choose energy-saving technologies just like users in commercial sector.
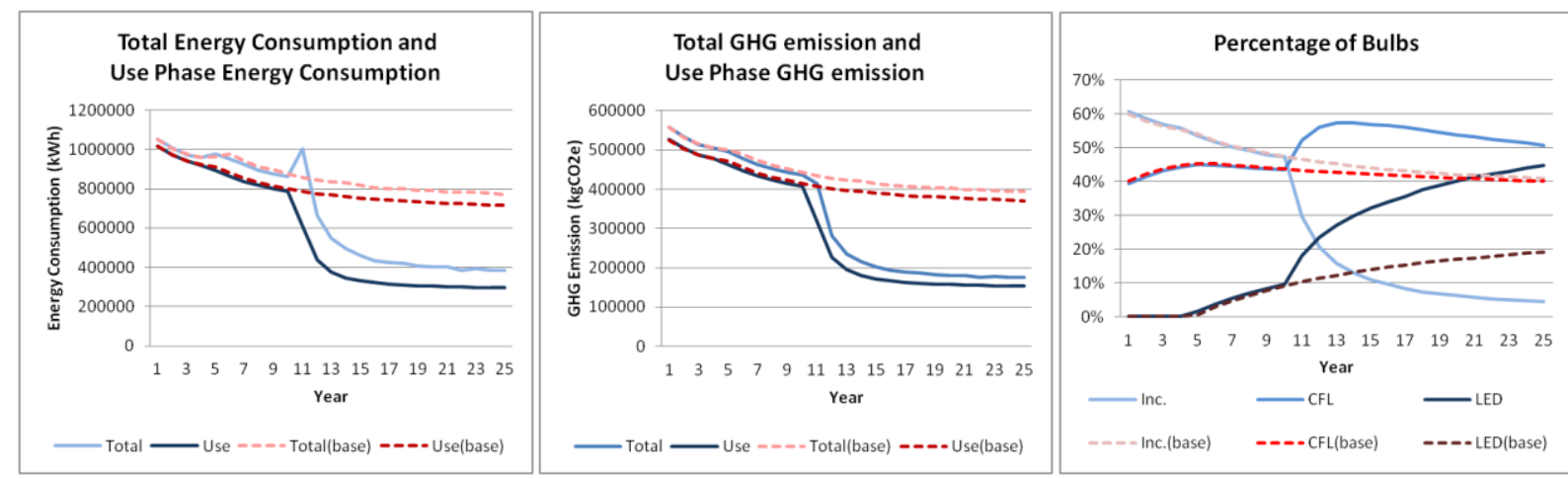

Figure 5: Incandescent Lamp Ban

Under incandescent lamp ban scenario, a sharp change in trend can be observed when ban comes into effect. Annual use phase energy consumption, annual total GHG emission and annual use phase GHG emission drastically fall, whereas a spike happens in annual total energy consumption. This is due to that fact that manufacturing CFL and LED bulbs is more energy intensive than incandescent bulbs. Besides, both CFL and LED bulbs have s-shape curve market share increase after incandescent bulbs are banned, but CFL bulbs are replaced by LED bulbs afterwards. Under this scenario, total energy consumption in year 2035 is reduced by $65 \%$, while use phase energy consumption is reduced by $72 \%$. Meanwhile, total GHG emission is reduced by $70 \%$. At the year of incandescent ban, a sudden increase of total energy consumption can be observed. As stated before, this is caused by higher manufacturing energy consumption of CFL and LED bulbs. However, with longer lifespan and higher use phase efficiency of these technologies, total energy consumption quickly falls afterwards. 

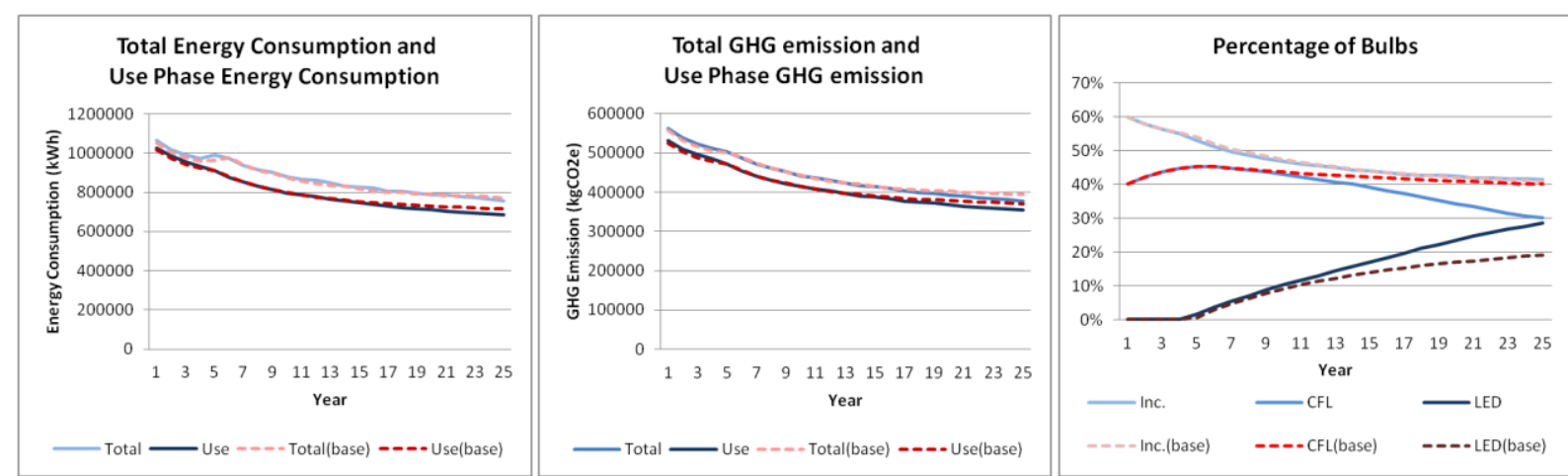

Figure 6: LED Advancement (EIA case)

If LED technology continues to develop as EIA estimated, LED lighting will have $29 \%$ market share at year 2035, which is roughly $50 \%$ higher than base case. However, as most replacement comes from CFL lighting, the total number of incandescent bulbs at year 2035 remains the same level with base case. Therefore, only slight improvements on energy consumption and GHG emission reduction are observed. Under this scenario, annual total energy consumption is reduced by $29 \%$, and use phase energy consumption is reduced by $34 \%$. For annual total GHG emission the reduction rate is $33 \%$.
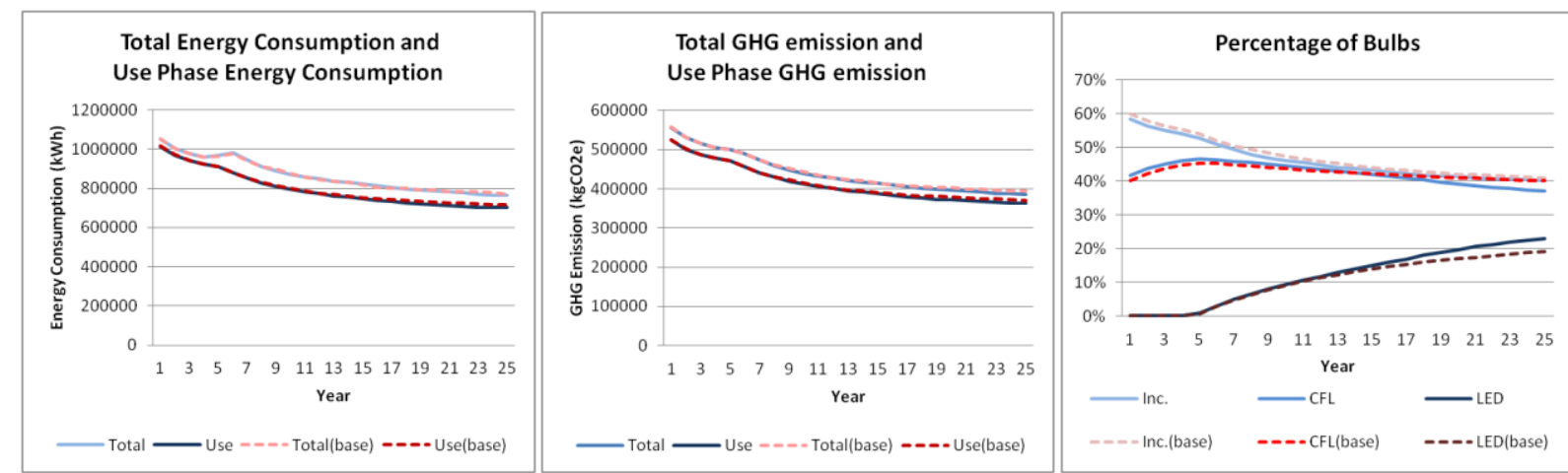

Figure 7: LED Advancement (conservative case)

For a more conservative LED technology advancement scenario, the result is very close to the base case. At year 2035, LED lighting will have $23 \%$ market share, which is $15 \%$ better than base case. However, energy consumption and GHG emission reduction rates are nearly the same as the base case. Comparing with EIA case, it is apparent to see that the advancement of LED technology still has a positive effect in increasing the market share of LED lighting. However, it is not able to push the fade out of incandescent, since in this model most incandescent users are not cost sensitive. 

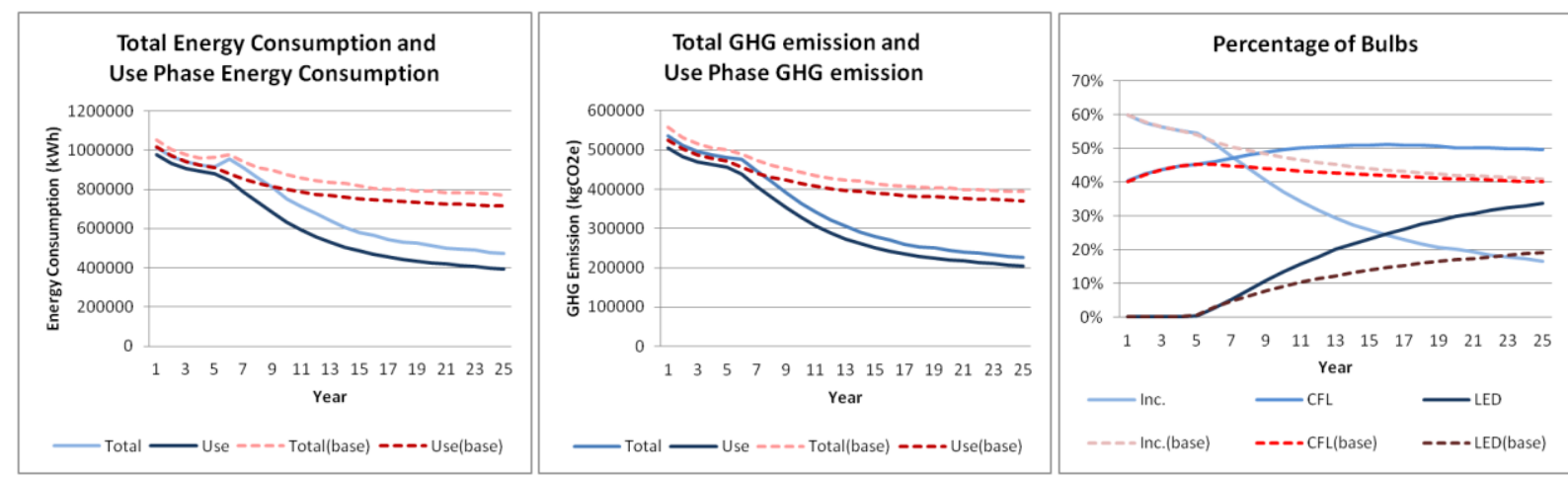

Figure 8: Energy Saving Campaign (slower case)

Under energy saving campaign scenario, the constant increase of attitudes toward highefficiency lightings causes incandescent lamps to fade out. At Year 2035, annual total energy consumption is reduced by $53 \%$ and annual use phase energy consumption is reduced by $60 \%$. Also, annual total GHG emission is reduced by $58 \%$. Although in reality, it is very hard to directly improve public opinion steady and fast like this, the scenario still shows that information plays a key role in residential lighting retrofitting process and further study should be focused on this.
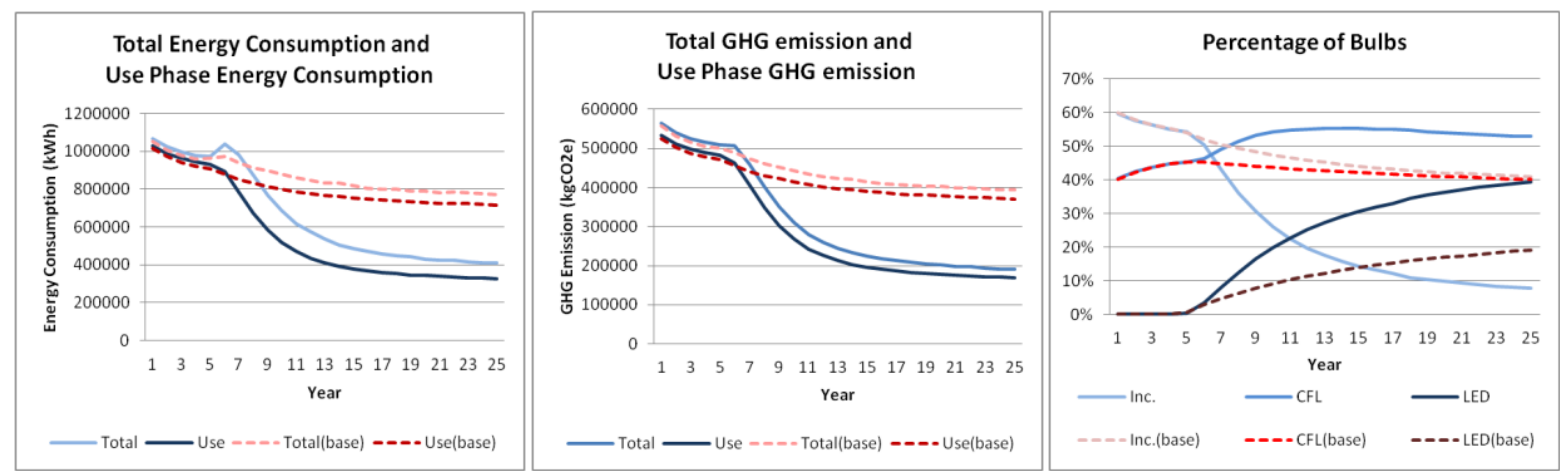

Figure 9: Energy Saving Campaign (faster case)

Under faster attitudes changes favoring high-efficiency lightings, the fade-out of incandescent becomes faster and more thoroughly. At year 2035, total energy consumption is reduced by $62 \%$ and use phase energy consumption is reduced by $68 \%$. Similarly, annual total GHG consumption is reduced by $66 \%$. With even faster improvements of households' attitude towards CFL and LED lighting, the result is very close to incandescent ban scenario.
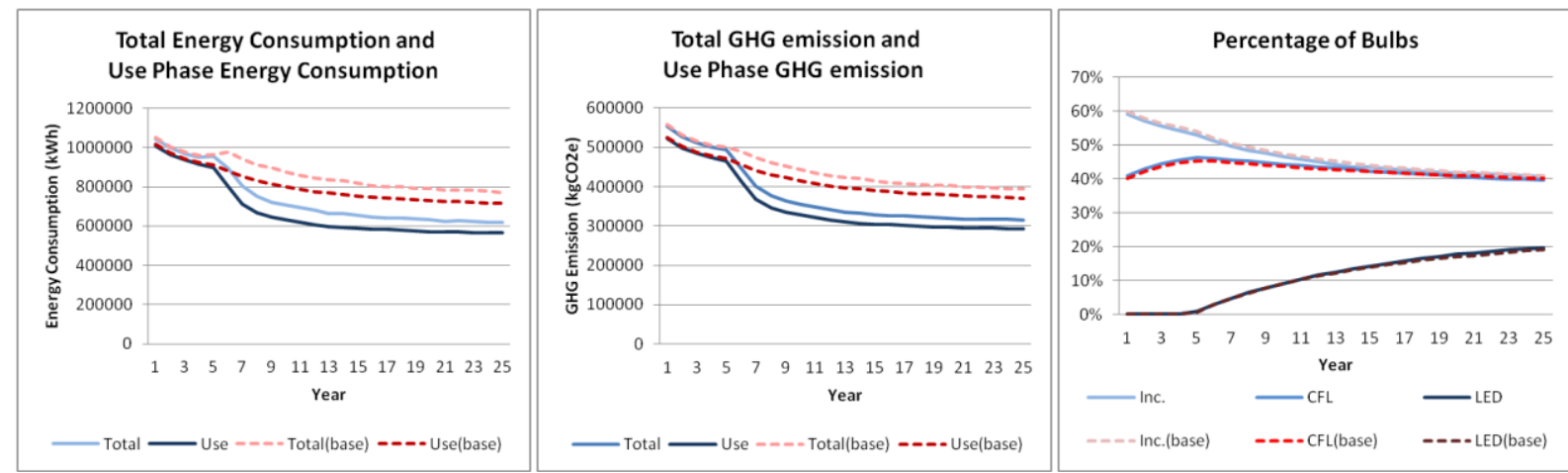

Figure 10: Energy Efficient Incandescent 
With energy efficient incandescent, although market share is similar with base case scenario, the reduction rates of energy consumption and GHG emission are higher. At year 2035, Total energy consumption is reduced by $41 \%$ and use phase energy consumption is reduced by $44 \%$. Besides, annual total GHG emission is reduced by $43 \%$. Although energy efficient incandescent still consume much more energy than CFL and LED lighting, such policy can reduce a significant amount of energy consumption and GHG emission provided that incandescent fade out is slow.

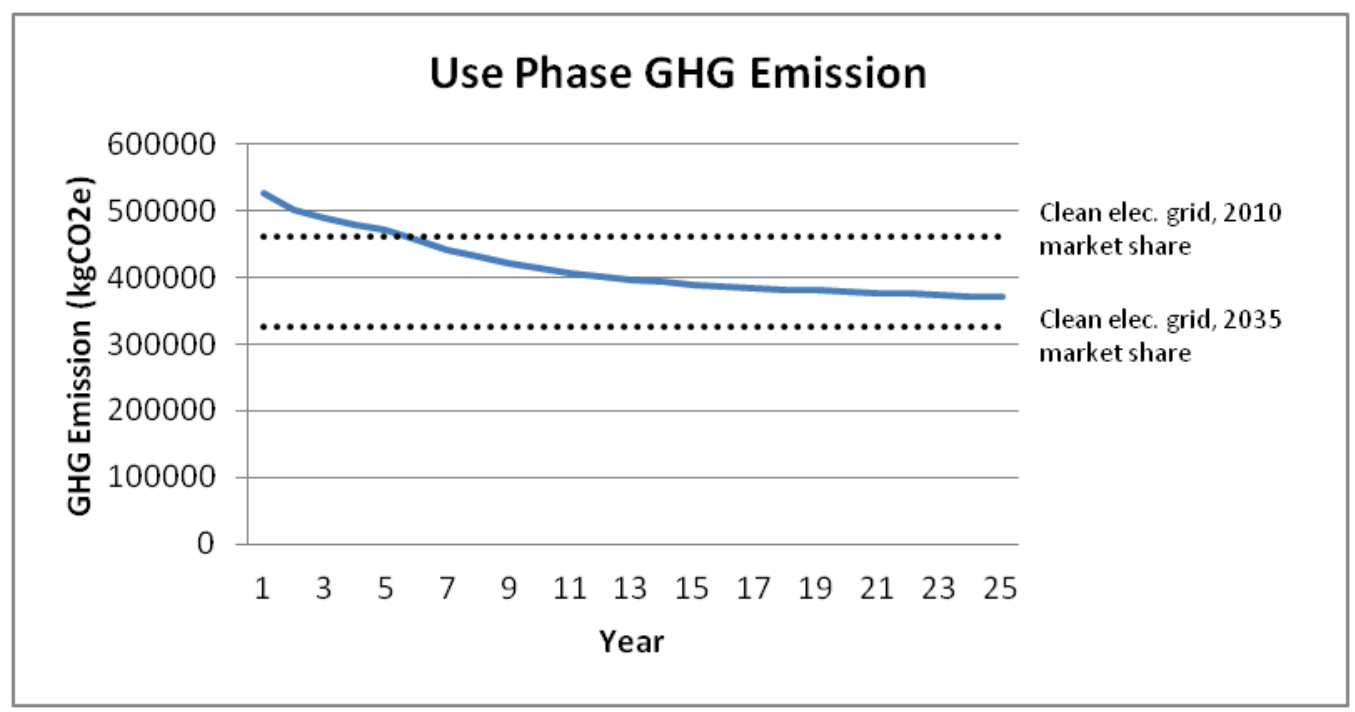

Figure 11: Base Case GHG Emission vs. Cleaner Electricity Grid

The annual GHG Emission with cleaner electricity grid is shown in Figure 11 as reference line. The line is calculated by combining cleaner electricity grid emission data (2035 projection) with lighting market share data from corresponding year. As stated above, when applying market share data from year 2010 , cleaner electricity grid alone can reduce GHG emission by $12 \%$. With base case, the reduction from high-efficiency lighting technologies will exceed this after 5 years. The result shows that high-efficiency lighting retrofitting plays an important role in reducing GHG emission from residential lighting sector. GHG emission reduction from incandescent fade out is greater than the reduction from electricity grid improvement.

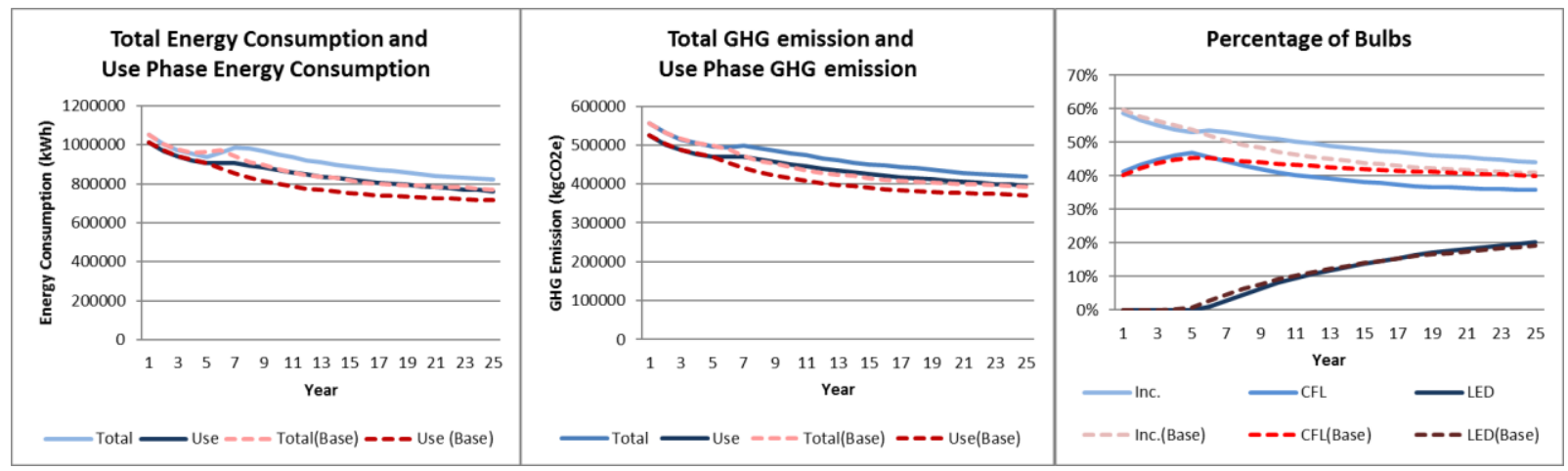

Figure 12: Mercury Issue

If mercury tax is applied and the public become more concern about mercury in CFL lighting, more households will stay with incandescent lamps. In this scenario, incandescent lamps stay with $5 \%$ more market share at year 2035 . Meanwhile, only $25 \%$ reduction of energy 
consumption and GHG emission is observed.
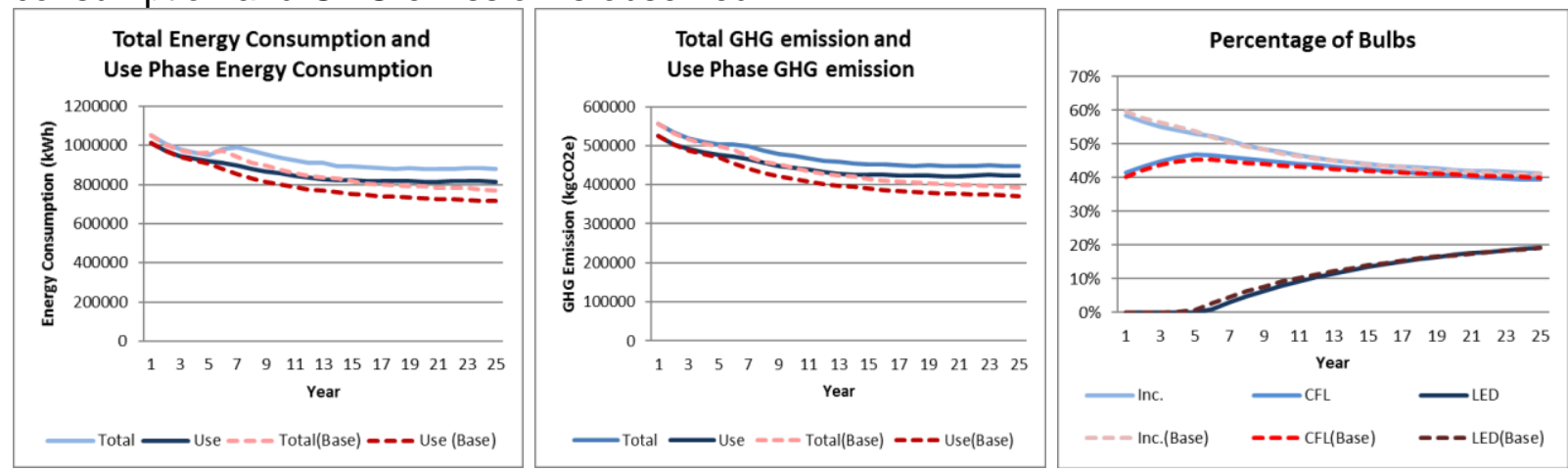

Figure 13: Rebound Effect

If rebound effect is considered, it is apparent to see that both energy consumption reduction and GHG emission reduction will be hindered. The result shows the same market penetration with the base case along the simulation. However, due to increased lighting time and lighting position, only $20 \%$ reduction can be observed on energy consumption and GHG emission. Therefore, if rebound effect happens in residential lighting market, it should be considered as an important negative factor to affect energy and GHG emission reduction.

\section{Conclusion and Future Work.}

In this study, an agent-based model is implemented to simulate the adoption of high-efficient lighting in a residential community. The result shows that a $30 \%$ of energy consumption and GHG emission reduction can be achieved by year 2035 with no policy applied. Furthermore, if there is an incandescent ban, the model projects $65 \%$ reduction of energy consumption and $70 \%$ reduction of $\mathrm{GHG}$ emission, which is the best among all scenarios. The result also shows that aside from direct ban of incandescent, it is more important to improve market share of highefficiency lighting than improve the efficiency of them. Therefore, proper way of marketing campaign can accelerate the reduction of energy consumption and GHG emission. Also, some factors, including health concerns and rebound effects, may have a negative effect in energy and GHG emission reduction. Finally, the model shows the importance of residential lighting retrofitting. There is a significant potential of energy saving and GHG emission reduction and the efficiency is better than mere improvement of electricity grid.

This model is very crude in the aspect of agent classification and behaviors. In fact, several possible factors can be detailed to improve model design. New smartphone applications will help households to calculate total lighting cost more precisely and may increase the number of rational users. CFL and LED lighting may have health issues, like emitting more blue light that is harmful before bedtime. Also, more cultural and political factors should be considered, as households with different backgrounds may response differently to new technology or government policies. Further study of the topic requires survey data on the customers, such as the one carried out by Hicks, A. L. et al. Deeper understanding of customer behavior can help improving the model and increasing its validity. Also, the model can be expanded in several ways. Commercial sectors can be integrated into the model and may affect the adoption process with its influence towards residential customers. Critical material consumption of the adoption process can be analyzed with expansion of the model. More detailed classification of lighting equipment, like the inclusion of halogen lamps and linear fluorescent bulbs can also be considered. 
Acknowledgement. This material is based upon work supported by the National Science Foundation under Grant No. 1336534. Any opinions, findings, and conclusions or recommendations expressed in this material are those of the authors and do not necessarily reflect the views of the National Science Foundation. 


\section{References}

[1] U.S. Energy Information Administration. (2014). Annual Energy Outlook 2014. United States Department of Energy.

[2] Navigant. (2012). 2010 U.S. Lighting Market Characterization. United States Department of Energy.

[3] Blok, K., Höhne, N., van der Leun, K., \& Harrison, N. (2012). Bridging the greenhouse-gas emissions gap. Nature Climate Change, 2(7), 471-474.

[4] Navigant. (2012). Life-Cycle Assessment of Energy and Environmental Impacts of LED Lighting Products. United States Department of Energy.

[5] Shahzada, K., Rehana, M., Ismaila, I. M., Sagirb, M., Tahirb, M. S., Bertokc, B., \& Nizami, A. S. (2015). Comparative Life Cycle Analysis of Different Lighting Devices. CHEMICAL ENGINEERING, 45.

[6] Bergesen, J. D., Tähkämö, L., Gibon, T., \& Suh, S. (2015). Potential Long - Term Global Environmental Implications of Efficient Light - Source Technologies. Journal of Industrial Ecology.

[7] Franz, M., \& Nicolics, J. (2015). Environmental aspects of white LED lighting systems: Energy statistics, study parameters, rare earths. In Electronics Technology (ISSE), 2015 38th International Spring Seminar on (pp. 396-401). IEEE.

[8] Cullen, T.. (2015). First Quarter Proves to be a Mixed Bag for Consumer Lamp Indexes. National Electrical Manufacturers Association

http://www.nema.org/news/Pages/First-Quarter-Proves-to-be-a-Mixed-Bag-for-Consumer-LampIndexes.aspx

[9] DNV GL. (2015). 2014-2015 Northwest Residential Lighting Long-Term Market Tracking Study. Northwest Energy Efficiency Alliance

[10] Richardson, I., Thomson, M., Infield, D., \& Delahunty, A. (2009). Domestic lighting: A highresolution energy demand model. Energy and Buildings, 41(7), 781-789.

[11] Johnson, B. J., Starke, M. R., Abdelaziz, O. A., Jackson, R. K., \& Tolbert, L. M. (2014, February). A method for modeling household occupant behavior to simulate residential energy consumption. In Innovative Smart Grid Technologies Conference (ISGT), 2014 IEEE PES (pp. 1-5). IEEE.

[12] Navigant. (2012). Energy Savings Potential of Solid-State Lighting in General Illumination Applications. United States Department of Energy.

[13] Chappin, E. J., \& Afman, M. R. (2013). An agent-based model of transitions in consumer lighting: Policy impacts from the EU phase-out of incandescents. Environmental Innovation and Societal Transitions, 7, 16-36. 
[14] Hicks, A. L., Theis, T. L., \& Zellner, M. L. (2015). Emergent effects of residential lighting choices: Prospects for energy savings. Journal of Industrial Ecology, 19(2), 285-295.

[15] Gilbert, G. N. (2008). Agent-based models (No. 153). Sage.

[16] Olshavsky, R. W., \& Granbois, D. H. (1979). Consumer decision making-fact or fiction?. Journal of Consumer Research, 93-100.

[17] Hoyer, W. D. (1984). An examination of consumer decision making for a common repeat purchase product. Journal of consumer research, 822-829.

[18] North, M. J., Collier, N. T., Ozik, J., Tatara, E. R., Macal, C. M., Bragen, M., \& Sydelko, P. (2013). Complex adaptive systems modeling with Repast Simphony. Complex adaptive systems modeling, 1(1), 1-26.

[19] Watts, D. J. (1999). Small worlds: the dynamics of networks between order and randomness. Princeton university press.

[20] DNV KEMA (2012). Residential Lighting End-Use Consumption Study: Estimation Framework and Initial Estimates

[21] U.S. Energy Information Administration. (2016). Electric Power Annual, DOE/EIA-0348. United States Department of Energy.

[22] U.S. Environmental Protection Agency (2015) The Emissions \& Generation Resource Integrated Database

https://www.epa.gov/energy/egrid

[23] Kelton, W. D., \& Law, A. M. (2000). Simulation modeling and analysis. Boston: McGraw Hill.

[24] U.S. Department of State, (2014). 2014 U.S. Climate Action Report

http://www.state.gov/documents/organization/219038.pdf

[25] Xiang, X., Kennedy, R., Madey, G., \& Cabaniss, S. (2005). Verification and validation of agent-based scientific simulation models. In Agent-Directed Simulation Conference (pp. 4755). 